\title{
Физико-химические свойства сорбента на основе силикагеля с привитым комплексом медьацетоуксусного эфира
}

\author{
(C) 2021 Пахнутова Е.А., Слижов Ю.Г. \\ Национальный исследовательский Томский государственный университет, Томск \\ Поступила в редакцию 15.02.2021 г.
}

DOI: $10.17308 /$ sorpchrom.2021.21/3637

Нанопористые минеральные оксиды способны радикально менять свои физико-химические свойства в результате химического модифицирования поверхности, что способствует развитию методов направленного синтеза материалов на их основе и широкому применению в условиях газовой хроматографии. Целью данной работы является получение газохроматографического сорбента с привитым слоем медьацетоуксусного эфира методом последовательной сборки на поверхности Силохрома С-120 через стадию его хлорирования.

Данные термического анализа свидетельствуют об устойчивости исследуемого комплекса этилацетоацетата меди до $210^{\circ} \mathrm{C}$. Методом адсорбционной порометрии установлено, что в результате химического модифицирования $\mathrm{SiO}_{2}$ происходит сокращение площади удельной поверхности и пористости. По результатам элементного анализа рассчитаны количество привитого слоя, поверхностная плотность привитых групп, толщина слоя этилацетоацетата меди на поверхности силикагеля.

Процессы адсорбции органических соединений (н-алканов, галогензамещенных алканов, 1нитропропана, гептена-1, ароматических углеводородов, кетонов и спиртов), способных к различным типам межмолекулярных взаимодействий с Силохромом С-120 и сорбентом на его основе исследованы газохроматографически. Модифицирование $\mathrm{SiO}_{2}$ этилацетоацетатом меди приводит к выраженному повышению констант Генри адсорбции спиртов, кетонов и ароматических углеводородов, обусловленному проявлением донорно-акцепторных, ориентационных и $\pi$-взаимодействий адсорбат-адсорбент. Рассчитанные термодинамические характеристики $\left(\overline{\mathrm{q}}_{d i f, l}\right.$ и $\left.\Delta \bar{S}_{1, C}^{S^{o}}\right)$ указывают $\Delta \bar{S}_{1, C}^{S^{o}}$ на повышение адсорбционного потенциала нового сорбента, отражающееся в возрастании теплот и энтропии адсорбции тестовых соединений. На основе экспериментальных данных определено, что химическое модифицирование $\mathrm{SiO}_{2}$ медьацетоуксусным эфиром приводит к увеличению вклада специфических взаимодействий в теплоту адсорбции, при этом наибольшие значения $\Delta \overline{\mathrm{q}}_{\mathrm{dif}, 1(\mathrm{c} п е щ)}$ характерны для органических соединений, склонных к образованию водородных связей и донорно-акцепторному комплексообразованию. Анализ компенсационных термодинамических зависимостей показал, что определяющим термодинамическим параметром при адсорбции органических соединений на исследуемых сорбентах является энтропия. Полученный сорбент апробирован для разделения смесей органических соединений различных классов, в числе которых предельные и непредельные углеводороды, спирты, альдегиды и кетоны.

Ключевые слова: силикагель, Силохром С-120, ацетоуксусный эфир, этилацетоацетат меди, газовая хроматография.

\section{Введение}

Химическое модифицирование адсорбентов комплексными соединениями позволяет регулировать сорбционные и селективные свойства полифункциональных материалов при использовании их в газовой хроматографии [1-3]. При этом важной задачей является целенаправленный выбор модификатора для получения адсорбента со свойствами, оптимальным образом подходящими для решения сложных задач хроматографического разделения [4].

Модифицирование кремнеземов хелатными комплексами ацетоуксусного 
эфира посредством последовательных химических реакций позволяет целенаправленно получать термостабильные хроматографические материалы, адсорбционные свойства поверхности которых определяются наличием нескольких активных центров в исследуемом хелате (электронодонорные атомы кислорода, $\pi$ системы), частичная компенсация электронного заряда атома металла за счет включения его в хелатное кольцо, создавая возможность специфических взаимодействий «адсорбат-адсорбент» различных типов [5]. При этом сочетание нескольких механизмов хроматографического удерживания и избирательность реакций комплексообразования дают преимущества перед неспецифичными адсорбентами, синтетическими полимерами, используемыми для разделения различных смесей органических соединений и концентрирования микропримесей [6-8].

Цель данной работы - синтез сорбента на основе Силохрома С-120 со слоем медьацетоуксусного эфира и изучение влияния поверхностно-привитого этилацетоацетата меди на термодинамику адсорбции органических веществ различных классов, а также возможности применения для селективных газохроматографических разделений многокомпонентных смесей.

\section{Экспериментальная часть}

Адсорбент с химически привитым слоем медьацетоуксусного эфира на поверхности кремнезема марки Силохром C-120 (0.20-0.35 мм) синтезировали методом последовательной сборки. На первом этапе $\mathrm{SiO}_{2}$ подвергали гидроксилированию путем кипячения в 10\% растворе азотной кислоты в течение 2 часов. Высушенный кремнезем хлорировали при комнатной температуре с применением $\mathrm{SOCl}_{2}$. Полученный натрацетоуксусный эфир растворяли в диметилформамиде и путем испарения растворителя наносили на поверхность Силохрома С-120. К мо- дифицированному ацетоуксусным эфиром кремнезему на заключительном этапе синтеза для формирования хелатного кольца добавляли спиртовой раствор хлорида меди.

ИК- и КР-спектрометрические исследования для подтверждения строения эилацетоацетата меди и закрепления его на Силохроме C-120 проводили на спектрометрах «Agilent Technologies» и «Nicolet NXR 9650» соответственно.

Параметры площади удельной поверхности и пористость исходного и химически модифицированного $\mathrm{SiO}_{2}$ оценивали из изотерм низкотемпературной адсорбции азота после вакуумирования исследуемых материалов при $200^{\circ} \mathrm{C}$ в течение 120 минут (газо-адсорбционный анализатор «TriStar II», метод БЭТ).

Термическую стабильность хроматографических сорбентов изучали по результатам термогравиметрии («Netzsch STA 449 C», диапазон температур 25$1000^{\circ} \mathrm{C}$, скорость нагрева $10^{\circ} \mathrm{C} /$ мин).

Для выполнения элементного анализа навеску вещества массой порядка 1 мг сжигали при температуре $1000-1100^{\circ} \mathrm{C}$ в окислительной среде в атмосфере гелия (автоматизированный HCNS-элементный анализатор «Euro EA-3000», ПО Callidus 5.1).

По данным адсорбционной порометрии и результатам HCNS-анализа о содержании углерода в исследуемых образцах рассчитывали толщину слоя, количество привитого ацетоуксусного эфира, поверхностную концентрацию хелатных комплексов при условии образования монослоя на поверхности $\mathrm{SiO}_{2}$ [1].

Для исследования адсорбционных свойств химически модифицированного Силохрома применяли газохроматографический метод. Измерения осуществляли на газовом хроматографе «Chrom 5» с пламенно-ионизационным детектором с использованием стеклянных насадочных колонок (длина 1.2 м, внутренний диаметр 3 мм). Хроматографирование проводили в изотермическом режиме в интер 


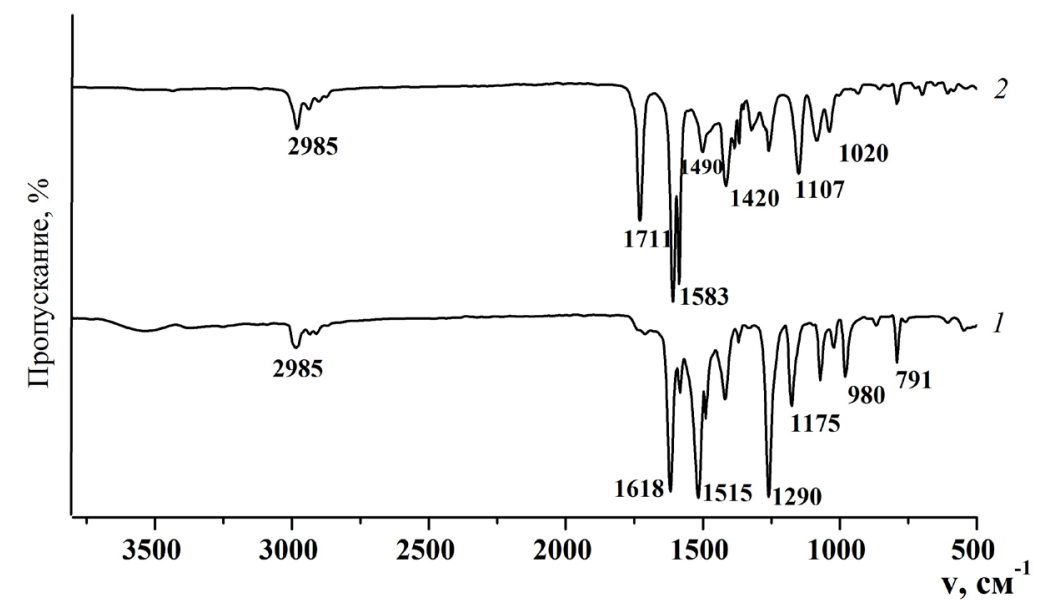

Рис. 1. ИК-спектры этилацетоацетата натрия (1) и вычитания $\mathrm{Si}-\mathrm{L}-\mathrm{Si}-\mathrm{Cl}$ на Силохроме C-120 (2)

Fig. 1. IR spectra of sodium ethylacetoacetate (1) and the $\mathrm{Si}-\mathrm{L}-\mathrm{Si}-\mathrm{Cl}$ subtraction on Silochrom S-120 (2)

вале температур от 140 до $200^{\circ} \mathrm{C}$ с постоянной скоростью газа-носителя (гелий) $30 \mathrm{~cm}^{3} /$ мин. В качестве адсорбатов выбирали органические вещества, склонные к различным типам межмолекулярных взаимодействий: донорно-акцепторные, ориентационные, дисперсионные, $\pi$-взаимодействия и др. Адсорбаты дозировали микрошприцем (0.05 мкл) в виде паровоздушных смесей, мертвое время удерживания определяли по метану.

По данным приведенных времен удерживания адсорбатов при разных температурах определяли удельные объемы удерживания $\mathrm{V}_{\mathrm{g}, 1}$, которые представляют собой константы Генри $\mathrm{K}_{1, C}\left(\mathrm{~cm}^{3} / \mathrm{M}^{2}\right)$ при малых объемах вводимой пробы [7] и тер модинамические характеристики адсорбции. На основании уравнения [9]

$$
\ln K_{1, C}=\frac{\bar{q}_{d i f, 1}}{R T}+\frac{\Delta S_{1, C}^{s^{0}}}{R}+1,
$$

рассчитывали $\overline{\mathrm{q}}_{\mathrm{dif}, 1}=-\overline{\mathrm{U}} \quad-$ дифференциальную молярную теплоту адсорбции и изменение стандартной дифференциальной молярной энтропии адсорбции [10].

Погрешность экспериментального определения величины $\mathrm{V}_{\mathrm{g}, 1}, \mathrm{~cm}^{3} /$ Г не превышала $4.5 \%$, величин дифференциальных молярных теплот адсорбции $\left(\overline{\mathrm{q}}_{d i f, 1}\right.$, кДж/моль) и изменений энтропии $\left(\Delta \bar{S}_{1, C}^{S^{0}}, \quad\right.$ Дж/(моль $\left.\left.\cdot \mathrm{K}\right)\right)$ адсорбции 2.9 кДж/моль и 7.0 Дж/(моль $\cdot \mathrm{K})$ соответственно.

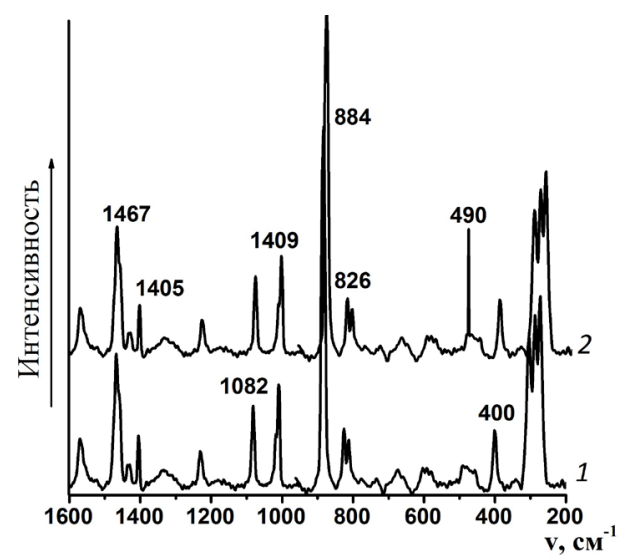

Рис. 2. КР-спектры ацетоуксусного эфира (1) и этилацетоацетата меди (2), привитых к поверхности Силохрома С-120.

Fig. 2. Raman spectra of acetoacetic ether (1) and copper ethylacetoacetate (2) grafted to the surface of Silochrom S-120. 
Таблица 1. Значения удельных площадей поверхности и геометрических характеристик пор для исследуемых адсорбентов.

Table 1. Values of specific surface areas and geometric characteristics of pores for the studied adsorbents.

\begin{tabular}{|c|c|c|c|c|c|}
\hline Адсорбент & $\begin{array}{c}\text { Sуд, } \mathrm{M}^{2} / \Gamma \text { (от- } \\
\text { нос. погреш- } \\
\text { ность } \Delta \pm 10 \%)\end{array}$ & $\begin{array}{c}\text { Суммарный } \\
\text { объем пор, } \\
\mathrm{cm}^{3} / \Gamma\end{array}$ & $\begin{array}{c}\text { Средний раз- } \\
\text { мер пор, нм }\end{array}$ & $\mathrm{C}_{\text {Бэт }}$ & $\mathrm{T}_{\max },{ }^{\circ} \mathrm{C}$ \\
\hline Силохром С-120 & 112 & 1.08 & 38 & 119 & - \\
\hline $\begin{array}{c}\text { Силохром С-120+ } \\
\text { этилацетоацетат меди }\end{array}$ & 83 & 0.83 & 32 & 112 & 210 \\
\hline
\end{tabular}

Вклад энергии специфического взаи-

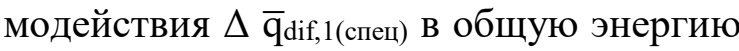
адсорбции оценивали для специфически адсорбирующихся тестовых соединений, по разности $\overline{\mathrm{q}}_{\mathrm{dif}, 1}$ адсорбата и неспецифически адсорбирующего нормального алкана с тем же значением поляризуемости $\alpha[11]$ :

$$
\Delta \overline{\mathrm{q}}_{d i f, 1(\text { спец })}=\overline{\mathrm{q}}_{\text {dif,l(сорбата) }}-\overline{\mathrm{q}}_{d i f, 1 \text { (н-алкана). }}
$$

\section{Обсуждение результатов}

На рис. 1 представлены ИК-спектры вычитания, в которых присутствуют характеристические полосы поглощения основных колебаний функциональных групп этилацетоацетата меди, полностью совпадающих с колебаниями натриевой соли ацетоуксусного эфира. В области $980 \mathrm{~cm}^{-1}$ полученные спектры содержат валентные колебания $\mathrm{v}\left(\mathrm{C}-\mathrm{CH}_{3}\right)$ связей. Деформационные колебания метильных групп представлены полосами поглощения $1010,1020 \mathrm{~cm}^{-1}, \delta(\mathrm{C}-\mathrm{H})$ связи описываются полосой поглощения $1175 \mathrm{~cm}^{-1}$. Валентные ассиметричные колебания связей $\mathrm{V}_{\text {as }}(\mathrm{C}-\mathrm{O}-\mathrm{C})$ сложноэфирной группировки этилацетоацетата представлены в спектре полосой с максимумом в области $1260 \mathrm{~cm}^{-1}$. Система валентных $\mathrm{v}(\mathrm{C}=\mathrm{O})$ и деформационных $\delta(\mathrm{C}-\mathrm{H})$ колебаний характеризуется набором полос поглощения 1490, 1501, $1508 \mathrm{~cm}^{-1}$. В области 1397 и $1420 \mathrm{~cm}^{-1}$ присутствуют полосы, описывающие сумму валентных и деформационных колебаний v $(\mathrm{C}-\mathrm{C}=\mathrm{C}-\mathrm{O})+\delta(\mathrm{OH})+$ $\delta(\mathrm{C}-\mathrm{H})+\mathrm{v}\left(\mathrm{C}-\mathrm{CH}_{3}\right)$. Сопряженная система связей $\mathrm{v}(\mathrm{C}=\mathrm{C}-\mathrm{C}-\mathrm{O})$ представлена в ИКспектре вычитания поглощением $1583 \mathrm{~cm}^{-1}$.
Максимум $1618 \mathrm{~cm}^{-1}$ в спектрах ацетоуксусного эфира принадлежит валентным симметричным колебаниям связи $(\mathrm{C}=\mathrm{O})$ [12].

При формировании хелатного кольца в результате обработки модифицированного этилацетоацетатом кремнезема раствором хлорида меди, образующаяся связь медь-кислород, описывается в КРспектре колебанием $490 \mathrm{~cm}^{-1}$ (рис. 2). В области $1467 \mathrm{~cm}^{-1}$ проявляются деформационные колебания $\delta\left(\mathrm{CH}_{3}\right)$, интенсивная полоса $1405 \mathrm{~cm}^{-1}$ описывают сумму $\mathrm{v}(\mathrm{C}$ $\mathrm{C}=\mathrm{C}-\mathrm{O})+\delta(\mathrm{OH})+\delta(\mathrm{C}-\mathrm{H})+\mathrm{v}\left(\mathrm{C}-\mathrm{CH}_{3}\right) . \mathrm{B}$ областях 1082 и $1009 \mathrm{~cm}^{-1}$ активны валентные колебания $\mathrm{v}(\mathrm{C}-\mathrm{C})$, a также $\rho\left(\mathrm{CH}_{3}\right)$. Максимумы 884 и $826 \mathrm{~cm}^{-1}$ характеризуют v $\left(\mathrm{C}-\mathrm{CH}_{3}\right)+\mathrm{v}(\mathrm{C}-\mathrm{O})$. Трехгорбый пик, колебания которого проявляются в низкочастотной области 273-274 cм-1, относятся к колебаниям хелатного кольца [12].

Согласно данным таблицы 1 химическое модифицирование кремнезема хелатным комплексом этилацетоацетата меди приводит к уменьшению пористости (табл. 1), площади удельной поверхности от 112 до $83 \mathrm{~m}^{2} /$ Г и адсорбционной константы БЭТ. Сужение пористости $\mathrm{SiO}_{2}$ при образовании поверхностно-привитого слоя, связано, вероятно, с заполнением мелких пор хелатом.

Термогравиметрическое исследование показало, что комплекс медьацетоуксусного эфира устойчив на поверхности кремнезема до $210{ }^{\circ} \mathrm{C}$ (табл. 1). 


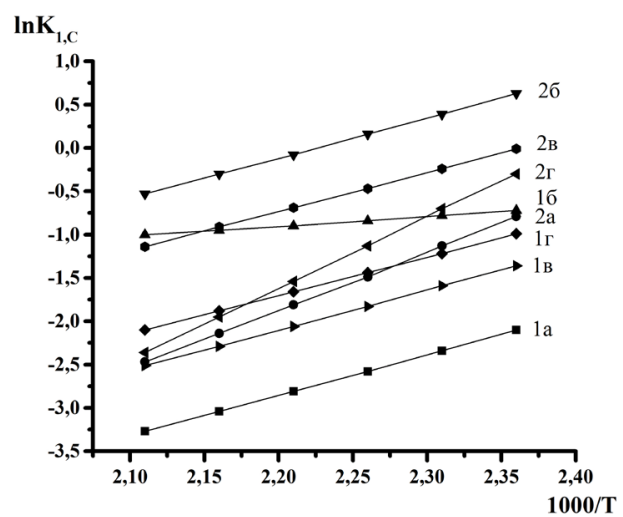

Рис. 3. Зависимости логарифма константы Генри адсорбции бензола (a),

бутанона-2 (б), нитропропана (в) и этанола (г) от обратной температуры на исходном Силохроме C-120 (1) и химически модифицированном этилацетоацетатом меди (2).

Fig. 3. Dependences of the logarithm of the Henry constant of adsorption of benzene (a), butanone-2 (b), nitropropane (c), and ethanol (d) on the reciprocal temperature on the initial Silochrom S-120 (1) and chemicallv modified copper ethvlacetoacetate (2)

Результаты исследования химического состава модифицированного Силохрома C-120 по данным HCNS-элементного анализа свидетельствуют о том, что количество привитого слоя этилацетоацетата меди составляет 0.56 ммоль/г, поверхностная плотность привитых групп 5.12 мкмоль $/ \mathrm{M}^{2}$, толщина привитого слоя 0.102 нм.

Методом газовой хроматографии были изучены процессы адсорбции органических соединений (н-алканов, галогензамещенных алканов, 1-нитропропана, гептена-1, ароматических углеводородов, кетонов и спиртов), способных к различным типам межмолекулярных взаимодействий с Силохромом C-120 и сорбентом на его основе, модифицированным медьацетоуксусным эфиром. Термодинамические характеристики адсорбции тестовых соединений определены на основе экспериментально полученных величин удельных удерживаемых объемов [13].

На рисунке 3 представлены температурные зависимости логарифма констант Генри $\left(\mathrm{K}_{1, C}\right)$ адсорбции соединений различных классов на исследуемых материалах. Для сорбентов характерна линейная зависимость между $\ln K_{1, C}$ сорбатов и 1000/Т и монотонное уменьшение значений $\mathrm{K}_{1, C}$ с ростом температуры. В случае адсорбции алканов, хлоралканов, алкенов, нитропропана изменений угла наклона прямых $\ln \mathrm{K}_{1, \mathrm{C}}-1000 / \mathrm{T}$ не происходит. Модифицирование Силохрома C120 этилацетоацетатом меди приводит к выраженному повышению значений констант Генри адсорбции (табл 2) спиртов, кетонов и ароматических углеводородов, при этом наблюдается увеличение угла наклона прямой зависимости $\ln K_{1, C}$ от 1000/Т, что связано с появлением активных центров поверхности различной силы и концентрации, способных к проявлению ориентационных, донорно-акцепторных и $\pi$-взаимодействий адсорбатадсорбент [14], а также указывает на отличие вклада модификатора в энтропийную составляющую энергии адсорбции.

Изменения $\mathrm{K}_{l, C}$ связаны с действием энергетического и энтропийного факторов на процесс адсорбции. На основе графических зависимостей логарифмов констант Генри от обратной температуры были рассчитаны дифференциальные молярные теплоты и изменения энтропии адсорбции, приведенные в таблице 2. Полученные термодинамические характеристики указывают на повышение адсорбционного потенциала сорбента в результате химического модифицирования поверхности $\mathrm{SiO}_{2}$, отражающееся в возрас 
Таблица 2. Константы Генри адсорбции $\left(\mathrm{K}_{1, C}\right)$, значения $\mathrm{K}_{1, C(\text { модиф) }} K_{1, C(I)}$, величины $\overline{\mathrm{q}}_{\mathrm{dif}, 1}$ и $-\Delta S_{1, C}^{S^{0}}$ тестовых соединений на исходном Силохроме C-120 (I) и модифицированном этилацетоацетатом меди (II).

Table 2. Henry adsorption constants $\left(\mathrm{K}_{1, C}\right)$, the values of $\mathrm{K}_{l, C(\text { modif })} \mathrm{K}_{1, C(I)}, \overline{\mathrm{q}}_{\mathrm{dif}, 1,1}$, and $-\Delta S_{1, C}^{S^{0}}$ for the tested compounds on the initial Silochrom S-120 (I) and the Silochrom S-120 modified with copper ethylacetoacetate (II).

\begin{tabular}{|c|c|c|c|c|c|c|c|}
\hline \multirow{2}{*}{ Соединение } & \multicolumn{2}{|c|}{$K_{l, C}\left(\mathrm{~cm}^{3} / \mathrm{M}^{2}\right)$} & \multirow{2}{*}{$K_{l, C \text { (модиф }) / K_{l, C(I)}}$} & \multicolumn{2}{|c|}{$\overline{\mathrm{q}}_{\text {dif, }, 1}$} & \multicolumn{2}{|c|}{$-\Delta S_{1, C}^{S^{0}}$} \\
\cline { 2 - 3 } & $\mathrm{I}$ & $\mathrm{II}$ & $\mathrm{II}$ & $\mathrm{I}$ & $\mathrm{II}$ & $\mathrm{I}$ & $\mathrm{II}$ \\
\hline н-Гексан & 0.04 & 0.11 & 2.95 & 11.5 & 40.9 & 59.3 & 121.9 \\
\hline н-Гептан & 0.09 & 0.24 & 2.66 & 18.7 & 42.9 & 70.5 & 125.9 \\
\hline н-Октан & 0.17 & 0.39 & 2.24 & 25.8 & 46.8 & 74.9 & 130.2 \\
\hline н-Нонан & 0.30 & 0.57 & 1.90 & 30.3 & 49.5 & 89.9 & 132.4 \\
\hline ССl & 0.05 & 0.12 & 2.36 & 11.1 & 48.3 & 44.8 & 143.0 \\
\hline Хлороформ & 0.04 & 0.09 & 2.20 & 6.9 & 43.8 & 33.9 & 133.6 \\
\hline $\begin{array}{c}\text { 1,2-Дихлор- } \\
\text { этан }\end{array}$ & 0.08 & 0.21 & 2.58 & 1.9 & 50.0 & 21.7 & 143.5 \\
\hline Нитропропан & 0.26 & 0.99 & 3.83 & 18.4 & 55.3 & 48.9 & 140.1 \\
\hline Бензол & 0.12 & 0.20 & 1.69 & 26.8 & 48.4 & 88.1 & 138.3 \\
\hline Толуол & 0.23 & 0.34 & 1.47 & 20.4 & 43.3 & 66.1 & 121.9 \\
\hline о-Ксилол & 0.33 & 0.90 & 2.73 & 27.9 & 46.6 & 83.6 & 119.2 \\
\hline п-Ксилол & 0.43 & 0.68 & 1.58 & 26.9 & 48.3 & 76.5 & 125.9 \\
\hline Мезитилен & 0.59 & 1.48 & 2.51 & 36.9 & 50.6 & 92.2 & 124.7 \\
\hline Псевдокумол & 0.67 & 1.62 & 2.42 & 37.8 & 50.2 & 100.8 & 127.8 \\
\hline Этанол & 0.40 & 0.74 & 1.84 & 36.9 & 63.9 & 102.8 & 160.2 \\
\hline Пропанол & 0.58 & 1.08 & 1.89 & 48.0 & 66.7 & 123.7 & 163.6 \\
\hline Бутанон-2 & 0.49 & 1.85 & 3.80 & 9.4 & 47.5 & 36.5 & 120.3 \\
\hline Гептен-1 & 0.15 & 0.30 & 2.00 & 23.7 & 50.3 & 77.8 & 141.4 \\
\hline
\end{tabular}

тании теплот адсорбции тестовых соединений (на 10-37 кДж/моль). При этом увеличение $\overline{\mathrm{q}}_{d i f, 1}$ наблюдается для алифатических углеводородов вследствие роста дисперсионных взаимодействий до 20 кДж/моль. Для хлорорганических веществ значения $\overline{\mathrm{q}}_{d i f, 1}$ возрастают от 2 кДж/моль для исходного кремнезема и до 48 кДж/моль в случае модифицированного этилацетоацетатом меди. Для ряда алкилбензолов, склонных к $\pi$-комплексообразованию с хелатами ацетоуксуного эфира, изменения $\overline{\mathrm{q}}_{d i f, 1}$ составляют порядка 20 кДж/моль. В случае ориентационных взаимодействий теплота адсорбции возрастает до 38 кДж/моль (для кетонов) и образования водородных связей - до 27 кДж/моль (для спиртов). Изменение энтропии органического соединения при переходе от исходного Силохрома C-120 к поверхностно- привитому со слоем хелата металла свидетельствует об изменении подвижности молекул адсорбатов в адсорбированном состоянии. Увеличение абсолютных величин энтропии адсорбции на модифицированных сорбентах позволяет сделать вывод о снижении подвижности адсорбатов на хелатсодержащей поверхности. Наиболее выраженный эффект наблюдается для алкенов, нитропропана, бутанона-2 и хлоралканов.

Для оценки суммарного вклада специфических, ориентационных, и индукционных взаимодействий адсорбат-адсорбент в общую энергию адсорбции на основе графических зависимостей (рис. 4) рассчитывали значения $\Delta \overline{\mathrm{q}}_{d i f, 1}$ (спец) различных тестовых веществ, сопоставляя полученные экспериментальные данные c $\overline{\mathrm{q}}_{d i f, l}$ гипотетического н-алкана с тем же 


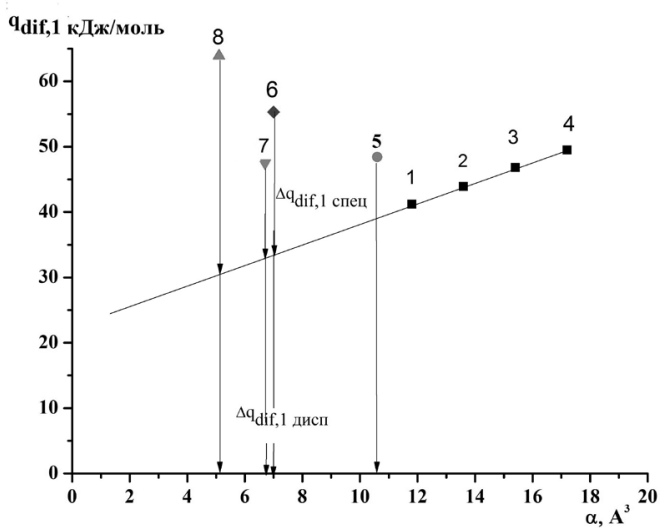

Рис. 4. Зависимость теплоты адсорбции от поляризуемости для Силохрома C-120, модифицированного этилацетоацетатом меди: 1 - н-гексан, 2 - н-гептан, 3 - н-октан, 4 - н-нонан, 5 - бензол, 6 - нитропропан, 7 - бутанон-2, 8 - этанол.

Fig. 4. Dependence of the heat of adsorption on polarisability for Silochrom

S-120 modified with copper ethylacetoacetate: (1) n-hexane, (2) n-heptane, (3) n-octane, (4) n-nonane, (5) benzene, (6) nitropropane, (7) butanone-2, (8) ethanol.

значением поляризуемости [15]. В качестве примера на рис. 4 приведены зависимости теплоты $\overline{\mathrm{q}}_{d i f, 1}$ от поляризуемости $\alpha$ тестовых веществ для Силохрома С-120 с привитым слоем этилацетоацетата меди.

Согласно данным таблицы 3 для исследуемых сорбентов наблюдается большой вклад протоно-акцепторных взаимодействий в общую энергию адсорбции, особенно для спиртов, что объясняется наличием гидроксильных групп на поверхности кремнеземов, склонных к образованию водородных связей. Величина $\Delta \overline{\mathrm{q}}_{d i f, l(\text { спец) }}$ для бутанона-2 достигает $65 \%$, для нитропропана - 39\% (проявление сильных донорно-акцепторных и ориентационных взаимодействий соответственно). Вклад $\Delta \overline{\mathrm{q}}_{d i f, l(\text { спец })}$ на С-120 для бензола составляет $16 \%$, на модифицированном образце $-22 \%$, т. е. возрастают $\pi$ взаимодействия.
Для полного сравнительного анализа свойств адсорбентов важно иметь представление о превалирующей роли термодинамических характеристик процесса. Для этого проведен анализ зависимостей между теплотой и энтропией адсорбции, на основании которых можно оценить, какой термодинамический фактор является определяющим. На рис.5 приведены зависимости между $\overline{\mathrm{q}}_{d i f, 1}$ и $\Delta \overline{\mathrm{S}}_{1, C}$ адсорбции для тестовых соединений на исследуемых адсорбентах. Из рис. 5 следует, что определяющую роль при адсорбции органических веществ на синтезированном хелатсодержащем сорбенте играет энтропийный фактор.

Сорбент на основе Силохрома С-120, химически модифицированный хелатом медьацетоуксусного эфира, применяли для газохроматографических разделений

Таблица 3. Значения энергии специфических $\Delta \mathrm{q}_{\mathrm{dif}, 1(\text { спец) }}$ взаимодействий для исходного Силохрома C-120 (I) и модифицированного этилацетоацетатом меди (II) и их вклад ( $\Delta \mathrm{q}_{\mathrm{dif}, 1 \text { (спец)/ }}$ $\left.\Delta_{\bar{q} \mathrm{dif}, 1}, \%\right)$ в общую энергию адсорбции.

Table 3. Energy values of specific $\Delta \mathrm{q}_{\mathrm{dif}, 1 \text { (spec) }}$ interactions for the initial Silochrom S-120 (I) and the Silochrom S-120 modified with copper ethylacetoacetate (II) and their contribution ( $\Delta \mathrm{q}_{\mathrm{dif}, 1(\mathrm{spec}) /}$ $\left.\Delta_{\bar{q} \text { dif, }, 1} \%\right)$ to the total adsorption energy.

\begin{tabular}{|c|c|c|c|c|}
\hline \multirow[b]{2}{*}{ Соединение } & $\Delta \mathrm{q}_{\mathrm{dif}, 1 \text { (спец) }}$ & $\Delta \mathrm{q}_{\mathrm{dif}, 1 \text { (спец) })} \Delta_{\overline{\mathrm{q}} \mathrm{dif}, 1,} \%$ & $\Delta \mathrm{q}_{\text {dif }, 1(\text { спец })}$ & $\Delta \mathrm{q}_{\mathrm{dif}, 1(\mathrm{c} \text { сец })} / \Delta_{\overline{\mathrm{q}} \mathrm{dif}, 1,} \%$ \\
\hline & \multicolumn{2}{|r|}{$\mathrm{I}$} & \multicolumn{2}{|r|}{ II } \\
\hline Бензол & 4.3 & 16 & 10.7 & 22 \\
\hline Нитропропан & 10.9 & 59 & 21.3 & 39 \\
\hline Бутанон-2 & 2.7 & 28 & 30.9 & 65 \\
\hline Этанол & 29.3 & 79 & 34.2 & 53 \\
\hline
\end{tabular}




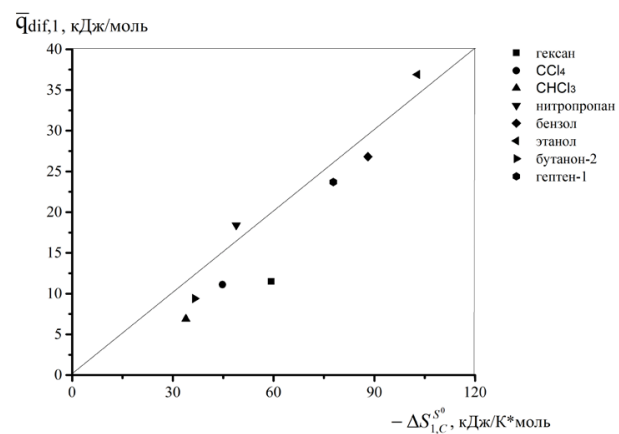

a

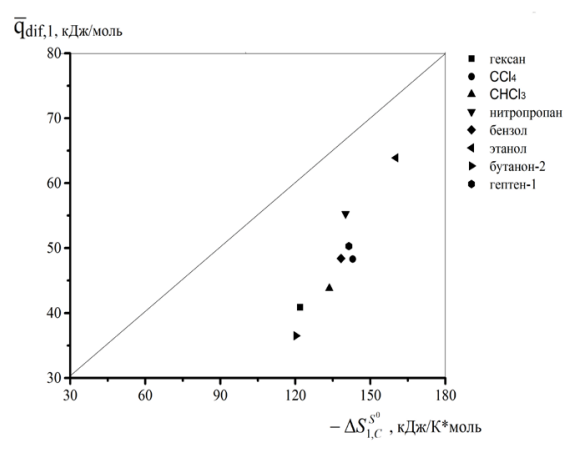

6

Рис. 5. Компенсационная зависимость между теплотой и изменением энтропии адсорбции для тестовых адсорбатов: а) Силохром С-120; б) Силохром С-120, модифицированный этилацетоацетатом меди.

Fig. 5. Compensation dependence between the heat and the change in adsorption entropy for tested adsorbates: a) Silochrom S-120; b) Silochrom S-120 modified with copper ethylacetoacetate.

сложных тестовых смесей разных классов органических соединений. За счет $\pi$ $\pi$ - взаимодействия кратной связи алкенов с активными центрами этилацетоацетата меди на исследуемом кремнеземе разделяются изобутилен и изобутан, пропилен и пропан.

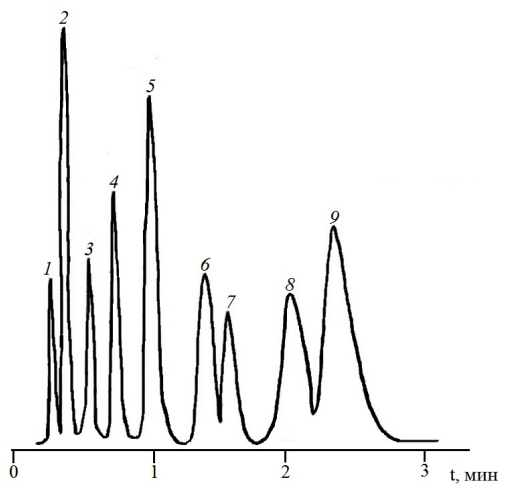

Рис. 6. Хроматограмма смеси углеводородов на Силохроме C-120 с привитым слоем этилацетоацетата меди в режиме программирования температуры от 40 до $80^{\circ} \mathrm{C}: 1$ - метан, 2 - этилен, 3 - этан, 4 - пропилен, 5 - пропан, 6 - изобутилен,

7 - изобутан, 8 - бутен- 1,9 - н-бутан.

Fig. 6 . A chromatogram of a mixture of hydrocarbons on Silochrom S-120 with a grafted layer of copper ethylacetoacetate in a temperature programming mode over a range extending from 40 to $80^{\circ} \mathrm{C}: 1$ - methane, 2 - ethylene, 3 - ethane, 4 - propylene, 5 - propane, 6 - isobutylene, 7 - isobutane, 8 - butene-1, 9 -n-butane.
Благодааря сильным донорно-акцепторным взаимодействиям и образованию Н-связей кислородсодержащих адсорбатов с поверхностью модифицированного Силохрома, в режиме программирования температуры удается провести селективное разделение модельной смеси кетонов (рис. 7).

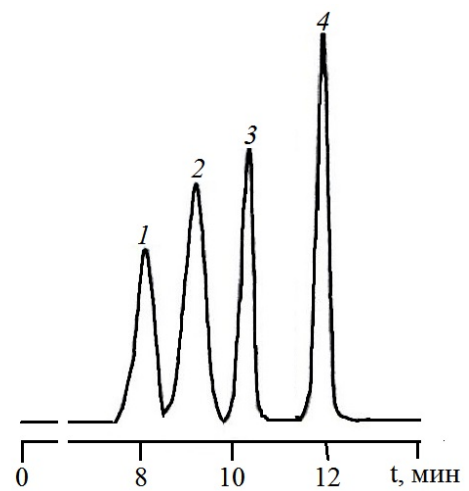

Рис. 7. Хроматограмма смеси кетонов на Силохроме C-120 с привитым слоем этилацетоацетата меди в режиме программирования температуры от 40 до $80^{\circ} \mathrm{C}$ :

1 - 5-метилгексанон-1, 2 - гептанон-2, 3 - 5метилгептанон-3, 4 - 2,6-диметилгептанон-2.

Fig. 7. A chromatogram of a mixture of ketones on Silochrom S-120 with a grafted layer of copper ethylacetoacetate in a temperature programming mode over a range extending from 40 to $80^{\circ} \mathrm{C}$ :

1 - 5-methylhexanone-1, 2 - heptanone-2, 3 -5methylheptanone- 3 , 4 -2,6-dimethylheptanone-2. 


\section{Заключение}

Для сорбентов на основе исходного и модифицированного Силохрома С-120 с химически привитым слоем этилацетоацетата меди изучены текстурные свойства поверхности, термическая устойчивость, рассчитана концентрация привитых групп.

При модифицировании $\mathrm{SiO}_{2}$ хелатом медьацетоуксусного эфира наблюдается рост констант Генри, теплоты и энтропии адсорбции по отношению ко всем сорбатам. Химическое модифицирование Силохрома С-120 приводит к увеличению вклада специфических взаимодействий в теплоту адсорбции, при этом наибольшие значения $\Delta \overline{\mathrm{q}}_{\text {dif,1(спец) }}$ характерны для органических соединений, склонных к образованию водородных связей и донорноакцепторному комплексообразованию. Анализ компенсационных термодинамических зависимостей показал, что определяющим термодинамическим параметром при адсорбции органических соединений на исследуемых сорбентах является энтропия.

Силохром-С120 с привитым слоем медьацетоуксусного эфира может применяться для газохроматографических разделений сложных органических смесей различных классов: предельных и непредельных углеводородов, спиртов, альдегидов и кетонов.

\section{Работа выполнена в рамках государственного задания Минобрнауки России (проект №0721-2020-0037).}

\section{Список литературы}

1. Лисичкин Г.В. Химия привитых поверхностных соединений. М. Физматлит. 2003. $592 \mathrm{c}$.

2. Wasiak W.J. // Chromatogr. A. 1993. Vol. 653. pp. 63-69.

3. Snow N. H. // Trends Analytical Chemistry. 2001. Vol. 21. No 9. pp. 608-617.

4. Ahn Y., Kwak S.-Y. // Microporous and Mesoporous Materials. 2020. Vol. 306. pp. 110410. DOI https://doi.org/10.1016/j.micromeso.2020.110410

5. Захарова Н.В., Сычев М.М., Корсаков В.Г., Мякин С.В. // Конденсированные среды и межфазные гранищы. 2011. Т. 13. № 1. С. 56-62.

6. Шмелев А.А., Филиппова Е.О., Шафигулин Р.В., Буланова А. // Сорбиионные и хроматографические проиессы. 2018. Т. 18. № 6. C. 836-843.

7. Рощина Т.М., Шония Н.К. // Журн. физ. химии. 2019. Т. 93. № 10. С. 1529-1537.
8. Pakhnutova E.A., Slizhov Yu.G. // Russian Journal of Physical Chemistry A. 2014. Vol. 88. Is. $\quad 8 . \quad$ pp. $1408-1412$. DOI: $10.1134 / \mathrm{S} 0036024414080214$

9. Авгуль Н.Н., Киселев А.В., Пошкус Д.П. Адсорбция газов и паров на однородных поверхностях. М. Химия. 1975. 384 с.

10.Онучак Л.А., Бурматнова Т.С., Спиряева Е.А. // Журн. физ. химии. 2012. Т. 86. № 8. С. 1424-1434.

11.Лопаткин А.А. // Росс. хим. журнал. 1996. T. 40. № 2. C. 5-18.

12.Накамото К. ИК-спектры и спектры КР неорганических и координационных соединений. М. Мир. 1991. 536 с.

13.Kowalczyk A., Borcuch A., Michalik M. // Microporous and Mesoporous Materials. 2017. Vol. 240. pp. 9-21.

14.Паркаева С.А., Белякова Л.Д., Ревина А.А. // Сорбиионные и хроматографические nроиессы. 2010. Т.10. № 5. C. 713-722.

15. Фаустова Ж.В., Пахнутова Е.А., Матвеева Т.Н., Слижов Ю.Г. // Вестник МГТУ им. Н.Э. Баумана. Сер. Естественные науки. 2018. № 2 (77). C. 114-125. 


\title{
Physical and chemical properties of a silica-based sorbent with a grafted complex of copper acetoacetic ester
}

\author{
(C) 2021 Pakhnutova E.A., Slizhov Yu.G. \\ National Research Tomsk State University, Tomsk
}

\begin{abstract}
Nanoporous mineral oxides can radically change their physical and chemical properties as a result of chemical modification of the surface. This is one of the reasons for the development of methods for the directed synthesis of materials based on nanoporous mineral oxides and their widespread use under the conditions of gas chromatography. The purpose of this work was to obtain a gas chromatographic sorbent with a grafted layer of copper acetoacetic ether by the method of sequential assembly on the surface of Silochrom S-120 which included the stage of its chlorination.

Thermal analysis data indicated the stability of the studied complex of copper ethylacetoacetate up to $210^{\circ} \mathrm{C}$. It was found by the method of adsorption porosimetry that the chemical modification of $\mathrm{SiO}_{2}$ results in a reduction in the specific surface area and porosity. The results of elemental analysis were used to calculate the amount of the grafted layer, the surface density of the grafted groups, and the thickness of the layer of copper ethylacetoacetate on the silica surface.

The adsorption processes of organic compounds (n-alkanes, halogen substituted alkanes, 1-nitropropane, heptene-1, aromatic hydrocarbons, ketones, and alcohols) capable of various types of intermolecular interactions with Silochrom S-120 and a sorbent based on it were studied by gas chromatography. $\mathrm{SiO}_{2}$ modification by copper ethylacetoacetate led to a pronounced increase in the Henry constants of adsorption of alcohols, ketones, and aromatic hydrocarbons due to occurrence of donor-acceptor, orientational, and $\pi$-interactions "adsorbate-adsorbent". The calculated thermodynamic characteristics $\left(\overline{\mathrm{q}}_{d i f, 1,}\right.$, and $\left.\Delta \bar{S}_{1, C}^{S^{0}}\right)$ indicated an increase in the adsorption potential of the new sorbent, which resulted in an increase in the heat and entropy of the adsorption of the tested compounds. The experimental data were used to determine that the chemical modification of $\mathrm{SiO}_{2}$ by copper acetoacetic ether leads to an increase in the contribution of specific interactions to the heat of adsorption. What is more, the largest values of $\Delta \overline{\mathrm{q}}_{\mathrm{dif}, 1(\mathrm{spec})}$ are characteristic of organic compounds prone to the formation of hydrogen bonds and donor-acceptor complex formation. The analysis of the compensating thermodynamic dependences showed that entropy is the key thermodynamic parameter during the adsorption of organic compounds on the studied sorbents. The resulting sorbent was tested for the separation of mixtures of organic compounds of various classes, including saturated and unsaturated hydrocarbons, alcohols, aldehydes, and ketones.
\end{abstract}

Keywords: silica, Silochrom S-120, acetoacetic ether, copper ethylacetoacetate, gas chromatography.

\section{References}

1. Lisichkin G. Khimija Privitykh Poverhnostnykh Soedinenij, M., Fizmatlit, 2003, 592 p.

2. Wasiak W., J. Chromatogr. A, 1993, Vol. 653, pp. 63-69.

3. Snow N.H., Trends Analytical Chemistry, 2001, Vol. 21, No 9, pp. 608-617.

4. Ahn Y., Kwak S.-Y., Microporous and Mesoporous Materials, 2020, Vol. 306, pp. 110410. DOI https://doi.org/10.1016/j.micromeso.2020.110410

5. Zaharova N.V., Sychev M.M., Korsakov V.G., Mjakin S.V., Kondensirovannye sredy $i$ mezhfaznye granicy, 2011, Vol. 13, No 1, pp. 5662.
6. Shmelev A.A., Filippova E.O., Shafigulin R.V., Bulanova A.V., Sorptsionnye i khromatograficheskie protsessy, 2018, Vol. 18, No 6, pp. 836-843.

7. Roshchina T.M., Shoniya N.K., Russ. J. Phys. Chem. A, 2019, Vol. 93, No 10, pp. 19311938.

8. Pakhnutova E.A., Slizhov Yu.G., Russian Journal of Physical Chemistry A, 2014, Vol. 88, Is. 8 , pp. $1408-1412$. DOI: $10.1134 / \mathrm{S} 003602441$ 4080214.

9. Avgul N.N., Kiselev A.V., Poshkus D.P., Adsorbciya Gazov I Parov Na Odnorodnyh Poverhnostyax. M., Khimiya, 1975, 384 p.

10. Onuchak L.A., Burmatnova T.S., Spiryaeva E.A., Russ. J. Phys. Chem. A, 2012, Vol. 86, No 8, pp. 1308-1317.

11.Lopatkin A.A., Rus. Chem. Journal, 1996, Vol. 40, No 2, pp. 5-18. 
12. Nakamoto K. IR spectra and Raman Spectra of Inorganic and Coordination Compounds. M., Mir, 1991, $536 \mathrm{p}$.

13.Kowalczyk A., Borcuch A., Michalik M., Microporous and Mesoporous Materials, 2017. Vol. 240. pp. 9-21.

Пахнутова Евгения Андреевна - к.х.н., инженер-исследователь лаборатории химической экологии, Томский государственный университет, Томск

Слижов Юрий Геннадьевич - к.х.н., декан химического факультета, доцент кафедры органической химии, Томский государственный университет, Томск
14.Parkaeva S.A., Belyakova L.D., Revina A.A., Sorptsionnye I khromatograficheskie protsessy, 2010, Vol. 10, No 5, pp 713-722.

15.Faustova Z.V., Pakhnutova E.A., Matveeva T.N., Slizhov Yu.G., Vestn. Mosk. Gos. Tech. Univ. im. N. E. Baumana, 2018, No 2 (77), pp. 114-125.

Pakhnutova Evgeniya A. - PhD, Research Engineer Chemical Ecology Laboratory, Tomsk State University, Tomsk, E-mail: pakhnutovae@mail.ru

Slizhov Yuriy G. - PhD, Dean of the Faculty of Chemistry, chair of organic chemistry, Tomsk State University, Tomsk, E-mail: decan@x.t.tsu.ru 